\section{The Placental Vascularization Indices Value and Placental Volume in Pregnancies with Antiphospholipid Syndrome for Pregnancy Outcome Prediction}

\author{
Yehia Ahmed Yehia Mohamed Gomaa ${ }^{1 *}$ M.B.B.Ch; Abd El Azem Mohamed Ahmed ${ }^{1}$ MD; Emad Mohamed \\ Ibrahim Mohamed Attallah ${ }^{1}$ MD
}

*Corresponding Author:

Yehia Ahmed Yehia Mohamed Gomaa yehiayehia991@yahoo.com

Received for publication February 11 , 2021; Accepted March 1, 2021;

Published online March 1, 2021.

Copyright 2020 The Authors published by Al-Azhar University, Faculty of Medicine, Cairo, Egypt. All rights reserved. This an openaccess article distributed under the legal terms, where it is permissible to download and share the work provided it is properly cited. The work cannot be changed in anyway or used commercially.

doi: 10.21608/aimj.2021.62702.1416

${ }^{1}$ Obstetrics and Gynecology Department, Faculty of Medicine, Al-Azhar University,Cairo,Egypt.

Disclosure: The authors have no financial interest to declare in relation to the content of this article. The Article Processing Charge was paid for by the authors.

Authorship: All authors have a substantial contribution to the article.

\begin{abstract}
Background: The detection of antiphospholipid antibodies in the setting of arterial and venous thrombus and/or pregnancy loss involves antiphospholipid syndrome. APS may be primary in $40 \%$ of instances where no proof of autoimmune disease is present, or secondary to autoimmune processes such as systemic erythematous lupus.

Aim of the work: To explore the value of placental volume and placental vascularization indexes for predicting pregnancy results in pregnant women with antiphospholipid syndrome.

Patients and Methods: One hundred pregnant women have been classified into 2 groups: Group A) group of controls (50 cases), (Group B) group of anti-phospholipids (50 cases). The perinatal results were associated with placental volume findings and indexes of placental vascularization. The precision in predicting the negative result was determined.

Results: The indexes of placental vascularization, VI, FI and VFI in group B became lower in 1st and 2nd US scans with statistically significant $\mathrm{P}$ values $(<0.05)$. Also placental volume was lower in antiphospholipid group in 1st and 2nd US scans with statistically significant $P$ values $(<0.001)$. A significant correlation was found among the two groups concerning the gestational age at termination of pregnancy, Apgar score and birth weight (with P-value < 0.05). Moreover, IUGR in group B was significantly associated with placental volume and placental vascularization indexes.

Conclusion: In women who are pregnant with antiphospholipid syndrome, placental volume and placental vascularization indexes are good methods for evaluating fetal well-being and predicting neonatal outcomes.
\end{abstract}

Keywords: placental volume; placental vascularization indices; antiphospholipid syndrome; neonatal outcome; IUGR.

\title{
INTRODUCTION
}

Anti-phospholipid antibody syndrome has been an autoimmune disease found mainly in young women. Abnormal proteins named anti-phospholipid autoantibodies are made in the blood by those with APS. This induces blood to flow unduly, which would contribute to the hazardous clotting of arteries and veins, problems for fetal development and miscarriage of pregnancy. Otherwise, individuals with this disorder may be healthy, or may have an underlying disease, the most often systemic erythematous lupus (commonly called lupus or SLE).

Autoantibodies directed toward phospholipid-binding proteins have been antiphospholipid antibodies. Lupus anticoagulant (LA) and anti-cardiolipin antibodies are among these antibody groups (aCL). Identification of antiphospholipid antibodies in arterial and venous thrombus settings and/or pregnancy loss involves antiphospholipid syndrome (APS). APS may be predominant in $40 \%$ of instances where there is no proof of autoimmune disease or where there is no evidence of autoimmune processes such as systemic lupus erythematosus (SLE). ${ }^{6}$

Since 2004, both placental volume and vascularization can currently be assessed using threedimensional ultrasound (3DUS). This method was used to measure three typical indices of an interest volume: the vascularization index (VI), flow index (FI) and vascularization-flow index (VFI). Few studies have examined the significance of this approach in evaluating of fetal growth restriction (FGR). In growth-restricted fetuses, such studies recorded lower placental vascular indices. Likewise, other additional research used the virtual organ computed-aided analysis (VOCAL) rotational technique to evaluate the placenta of growthrestricted fetuses, allowing vascular indices to be measured via the whole volume of placenta. The placental assessment shows that FGR is associated with declines in placental volume and vascular indices. $^{1}$ 


\section{PATIENTS AND METHODS}

The current research was performed with 100 pregnant women at Obstetrics and Gynecology Department, El-Hussein Hospital, Al-Azhar University, during the period from June 2020 till December 2020. Patients have been classified into two groups (Group A) containing 50 patients free of any medical disorder by history, and clinical review was considered control and (Group B) included 50 cases had anti-phospholipid syndrome fulfilling the inclusion and exclusion criteria.

The study included women with singleton pregnancy, $\geq 34$ weeks gestational age, antiphospholipid syndrome (1ry or 2ry APS) either alone or/and with hypertension or/and intrauterine growth restriction (IUGR) for group B. At least one laboratory and one clinical criterion should be fulfilled in order to diagnose APS.

Clinical criteria:

Vascular thrombosis:

One or more arterial, venous, or tiny vessel thrombosis episodes of any organ.

Morbidity of pregnancy: One or more fetal deaths of morphologically normal fetuses at or after ten weeks of pregnancy. One or more early deliveries of morphologically normal neonates prior to the 34th week of pregnancy. Prematurity must be secondary to placental insufficiency, eclampsia, or extreme preeclampsia (intrauterine growth restriction).

After excluding any maternal anatomical or hormonal anomalies and parental chromosome causes, three or more consecutive spontaneous abortions prior to the tenth week of pregnancy. ${ }^{6}$

Laboratory criteria: detection on two or more times of Lupus Anticoagulant in plasma, twelve weeks or more apart. Identification of IgG or IgM subtypes of anticardiolipin antibodies in serum or plasma determined by standard ELISA, two or more times 12 or more weeks apart. Identification of IgG and/or IgM isotype anti-b2 glycoprotein-I antibodies in serum or plasma as measured using standard ELISA, two or more times 12 or more weeks apart. ${ }^{6}$

Pregnant women who had any of the following conditions were excluded from the study: twin or multiple pregnancy, congenital fetal defects, pregnancy age lower than 34 weeks, Pregnant females with other medical problems (diabetes, history of heart or renal disease), women with defects of the placental or umbilical artery, hemorrhage of the antepartum (placental abruption, placenta previa and vasa previa), posterior placenta, history of membrane rupture, rejection or leakage of the patient.

Patients participating in the research would be subject to the following: A written informed consent. Full History Taking Including: Age. Gestational age, confirmed by the 1st day of her LMP or ultrasound examination during the 1st trimester. Gravidity and Parity Body Mass Index (BMI) = weight/ (height in meters) ${ }^{2}$.

Thorough Clinical Examination included general examination; included vital signs and full obstetric examination.
Ultrasound: Interval ultrasonographic biometry [biparietal diameter (BPD), head circumference (HC), femur length (FL), abdominal circumference (AC), and estimated fetal weight (EFW)], fetal lying, appearance, placental position, amniotic fluid evaluation and fetal abnormality exclusion. Doppler velocimetry was conducted on the umbilical artery (UA) and the middle cerebral artery (MCA). Placental volume was conducted for all cases using VOCAL technique. For automatic measurement of vascular indices, vascularization index (VI), flow index (FI) and vascularization flow index (VFI), the Power Doppler was activated. All the above ultrasonographic parameters were done twice, the 1st time at 34-37 weeks of gestation, and the 2nd one just before termination of pregnancy.

Neonatal assessment:

Any perinatal complications such as: perinatal death, low birth weight $<10$ th percentile are identified as adverse (or abnormal) perinatal outcomes. The weight of the low birth is below 2,500 g (up to and including 2,499 g). ${ }^{11}$ cesarean section for fetal distress, amniotic fluid staining with meconium, 5minute Apgar score $<7$ and stay $>24$ hours in the neonatal intensive care unit.

The perinatal results will be associated with the findings of placental vascularization indices, placental volume, umbilical artery (UA) and middle cerebral artery (MCA) Doppler Indices, and cerebroplacental ratio (CPR). The accuracy of placental vascularization indices, placental volume, UA and MCA Doppler Indexes and CPR has been measured to predict negative outcomes.

\section{Statistical Methods}

The following tests have been performed: When contrasting among two ways, independent-samples ttest of significance has been utilized. In order to compare ratios among qualitative parameters, the Chi-square (x2) significance test has been utilized. Analysis of the receiver operating characteristic (ROC curve) has been used to evaluate the overall parameter predictivity and to Identify the best cut-off value at that cut-off value with sensitivity and specificity detection. The confidence interval was set at $95 \%$ and the agreed margin of error was set to $5 \%$.

RESULTS

\begin{tabular}{||r|c|c|c|c||}
\hline & $\begin{array}{c}\text { Control } \\
\text { Group } \\
(\boldsymbol{n}=50)\end{array}$ & $\begin{array}{c}\text { Antiphospholipid } \\
\text { Group(n=50) }\end{array}$ & t-test & p-value \\
\hline \hline UA-PI (1st US) & $0.92 \pm 0.21$ & $0.88 \pm 0.22$ & 0.657 & 0.340 \\
\hline UA-RI (1st US) & $0.59 \pm 0.09$ & $0.58 \pm 0.10$ & 1.292 & 0.670 \\
\hline MCA-PI (1st & $1.98 \pm 0.43$ & $1.78 \pm 0.60$ & 0.210 & 0.109 \\
\hline MCA-RI (1st & $0.85 \pm 0.10$ & $0.79 \pm 0.18$ & 0.248 & 0.128 \\
\hline CPR (1st US) & $1.52 \pm 0.29$ & $1.50 \pm 0.36$ & 1.499 & 0.777 \\
\hline \hline
\end{tabular}

Table 1: Comparison between control group and Antiphospholipid group as Doppler indices in the first US scan.
Obstetrics and Gynecology 


\begin{tabular}{|c|c|c|c|c|}
\hline & $\begin{array}{l}\text { Control } \\
\text { Group } \\
(n=50)\end{array}$ & $\begin{array}{l}\text { Antiphospholipid } \\
\text { Group }(n=50)\end{array}$ & $t$-test & $p$-value \\
\hline UA-PI (2nd US) & $0.83 \pm 0.14$ & $0.90 \pm 0.20$ & 0.258 & 0.134 \\
\hline UA-RI (2nd US) & $0.54 \pm 0.06$ & $0.58 \pm 0.09$ & 0.104 & 0.054 \\
\hline MCA-PI (2nd US) & $1.66 \pm 0.32$ & $1.65 \pm 0.44$ & 1.637 & 0.848 \\
\hline MCA-RI (2nd US) & $0.78 \pm 0.09$ & $0.78 \pm 0.07$ & 1.737 & 0.900 \\
\hline CPR (2nd US) & $1.53 \pm 0.23$ & $1.44 \pm 0.30$ & 0.314 & 0.163 \\
\hline
\end{tabular}

Table 2: Comparison between control group and Antiphospholipid group as Doppler indices in the second US scan.

\begin{tabular}{|c|c|c|c|c||}
\hline & $\begin{array}{c}\text { Control } \\
\text { Group } \\
(\boldsymbol{n}=50)\end{array}$ & $\begin{array}{c}\text { Antiphospholipid } \\
\text { Group(n=50) }\end{array}$ & t-test & $\boldsymbol{p}$-value \\
\hline \hline $\begin{array}{c}\text { VI (Placental } \\
\text { V.I.) (1st US) }\end{array}$ & $38.36 \pm 11.67$ & $11.46 \pm 4.92$ & 4.916 & $<0.001^{* * *}$ \\
\hline $\begin{array}{c}\text { FI (Placental } \\
\text { V.I.) (1st US) }\end{array}$ & $34.47 \pm 4.76$ & $31.25 \pm 3.64$ & 3.004 & $0.003^{*}$ \\
\hline $\begin{array}{c}\text { VFI (Placental } \\
\text { V.I.) (1st US) }\end{array}$ & $12.82 \pm 4.83$ & $5.54 \pm 2.85$ & 5.837 & $<0.001^{* *}$ \\
\hline
\end{tabular}

Table 3: Comparison between control group and Antiphospholipid group as placental vascular indices in the first US scan.

\begin{tabular}{||c|c|c|c|c||}
\hline & $\begin{array}{c}\text { Control } \\
\text { Group } \\
(\boldsymbol{n}=50)\end{array}$ & $\begin{array}{c}\text { Antiphospholipid } \\
\text { Group(n=50) }\end{array}$ & t-test & p-value \\
\hline \hline $\begin{array}{r}\text { VI } \begin{array}{r}\text { (Placental } \\
\text { VI.) (2nd US) }\end{array} \\
38.73 \pm 11.99\end{array}$ & $10.44 \pm 3.93$ & 16.381 & $<0.001^{* *}$ \\
\hline $\begin{array}{r}\text { FI (Placental } \\
\text { VI.) (2nd US) }\end{array}$ & $34.21 \pm 5.33$ & $25.21 \pm 4.00$ & 7.658 & $<0.001^{* *}$ \\
\hline $\begin{array}{c}\text { VFI (Placental } \\
\text { VI.) (2nd US) }\end{array}$ & $13.09 \pm 4.99$ & $4.56 \pm 2.78$ & 9.336 & $<0.001^{* *}$ \\
\hline
\end{tabular}

Table 4: Comparison between control group and Antiphospholipid group as placental vascular indices in the second scan.

\begin{tabular}{|c|c|c|c|c|}
\hline & $\begin{array}{l}\text { Control } \\
\text { Group } \\
(n=50)\end{array}$ & $\begin{array}{c}\text { Antiphospholipid } \\
\operatorname{Group}(n=50)\end{array}$ & $t$-test & $p$-value \\
\hline 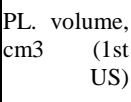 & $454.59 \pm 180.22$ & $312.63 \pm 87.68$ & 6.053 & $<0.001^{* *}$ \\
\hline $\begin{array}{l}\text { PL. volume, } \\
\mathrm{cm} 3 \quad \text { (2nd } \\
\text { US) }\end{array}$ & $527.90 \pm 194.09$ & $373.54 \pm 133.58$ & 8.019 & $<0.001^{* *}$ \\
\hline
\end{tabular}

Table 5: Comparison between control group and Antiphospholipid group as regard placental volume in the first and second US scans.

\begin{tabular}{||l|c|c|c|c||}
\hline & $\begin{array}{c}\text { Control Group } \\
(\mathbf{n}=50)\end{array}$ & $\begin{array}{c}\text { Antiphospholipid } \\
\text { Group(n=50) }\end{array}$ & $\boldsymbol{t}$-test & $\boldsymbol{p}$-value \\
\hline \hline $\begin{array}{l}\text { Apgar } \\
\text { (Neonate) }\end{array}$ & $8.71 \pm 0.80$ & $7.83 \pm 0.83$ & 5.991 & $<0.001^{* *}$ \\
\hline $\begin{array}{l}\text { Birth } \\
\text { weight } \\
\text { (Neonate) } \\
\text { gm }\end{array}$ & $3272.45 \pm 314.59$ & $2863.40 \pm 520.60$ & 7.953 & $<0.001^{* *}$ \\
\hline $\begin{array}{l}\text { GA at } \\
\text { termination } \\
\text { (Neonate) }\end{array}$ & $38.76 \pm 0.98$ & $37.14 \pm 0.59$ & 4.331 & $<0.001^{* *}$ \\
\hline
\end{tabular}

Table 6: Comparison between control group and Antiphospholipid group as regard GA at termination of pregnancy, Apgar score and birth weight.

\begin{tabular}{|c|c|c|c|c|}
\hline $\begin{array}{r}\text { NICU } \\
\text { admission } \\
\text { (Neonate) }\end{array}$ & $\begin{array}{l}\text { Control } \\
\text { Group } \\
(n=50)\end{array}$ & $\begin{array}{c}\text { Antiphospholipid } \\
\operatorname{Group}(n=50)\end{array}$ & $x^{2}$ & p-value \\
\hline Yes & $\begin{array}{c}1 \\
(2.0 \%)\end{array}$ & $4(8.0 \%)$ & \multirow{2}{*}{0.842} & \multirow{2}{*}{0.359} \\
\hline No & $\begin{array}{c}49 \\
(98.0 \%)\end{array}$ & 46 (92.0\%) & & \\
\hline
\end{tabular}

Table 7: Comparison between control group and Antiphospholipid group as regard NICU admission.

\section{DISCUSSION}

The present study was designed to assess the indexes of placental vascularization and placental volume in antiphospholipid syndrome pregnancies and their values for neonatal outcome predicting.

However, few research examined the significance of such technique in the evaluation of fetal growth restriction (FGR). Decreased placental vascular indexes in IUGR have been reported in these studies. Similarly, VOCAL rotational technique was used in other additional studies to assess the placentae of hypertensive pregnant women and growthrestricted fetuses, allowing vascular indexes to be measured over the entire volume of placentae. The whole assessment of the placentae showed that a decrease in placental volume and vascular indexes was associated with FGR and preeclampsia.

Accuracy of placental volume and vascular indexes in predicting negative outcomes were calculated, as primary outcome variable. Also, our study aimed to assess UA and MCA Doppler indexes in pregnant ladies with APS as secondary outcome variable.

The current study included 100 women, and was categorized in 2 groups, control group and antiphospholipid group. 
As regarding the findings of our study, placental vascularization index and placental volume were lower in anti-phospholipid group in 1st and 2nd US scans with statistically significant values than that of control group. Our results agreed with study done on 40 patients with preeclampsia, While various behaviors were observed in each of the indices, the 3D PD-US vascularity index was substantially associated with pregnancy age. Throughout pregnancy, the FI index rises linearly and gradually, the VI index rises until week 30 , and then hangs on the plateau value until week 37 , and then declines. In extreme preeclampsia, placenta FI, VI and VFI have been substantially lower than normal pregnancies. ${ }^{2}$

A further study was conducted by Chen et al., a prospective study of 27 preeclampsia-complicated singleton pregnancy and 41 normal pregnancy between 27 and 39 gestation weeks to assess vascularization alterations in 3DPD-assessed preeclamptic placenta and reported that vascular indexes in preeclamptic placentas were substantially lower relative to controls and that placental volumes in preeclampsia instances were decreased. ${ }^{4}$

In 2012, 388 females, 30 (7.7\%) PE, 37 (9.0\%) GH and $31(8.0 \%)$ SGA were evaluated by Odibo et al. In that study, it was shown that in pregnancies which subsequently developed PE, the average vascular index of first trimester placentas was lower than in unaffected pregnancies. Moreover, relative to normal controls, those pregnancies with both PE and SGA had a substantially lower FI. In addition, they observed that the average firsttrimester placental volumes were not significantly different relative to unaffected gestations in these pregnancies that developed PE. The latter outcome was different from the pregnancy results which developed GH and SGA, whereby the average volumes of placenta were smaller than normal controls. ${ }^{3}$

In the present study, low birth weight was significantly correlated to placental vascularization indices in the $1^{\text {st }}$ and the $2^{\text {nd }}$ scan. However it showed no significant correlation with VI in the $1^{\text {st }}$ scan. In the second US scan, which agreed with a study in 2015, evaluated 126 normotensive and 128 hypertensive pregnant ladies in a prospective casecontrol study from March 2011 to March 2013, placental volume was significantly lower in pregnant ladies who born a neonate with low birth weight. They found that low placental vascularization and higher umbilical artery S/D were observed in neonates infected with SGA. ${ }^{12}$

Also, in the current study, IUGR in APS group was significantly correlated to placental indices in the $1^{\text {st }}$ and the $2^{\text {nd }}$ scan. However it showed no significant correlation with VI in the $1^{\text {st }}$ scan. Placental volume was substantially lower for pregnant ladies who had born a neonate with IUGR in the 2nd US scan. However it showed no significant correlation with placental volume in the 1st scan.

Current study results regarding IUGR was agreed with a prospective case-control study done on 254 women concluded that in pregnancies complicated by IUGR, placental vascularization was decreased. Median VI became in the IUGR group at $3.7 \%$ (interquartile range [IQR] $3.2 \%-4.2 \%$ ) and in the control group at $10.1 \%$ (IQR $8.6 \%-10.9 \%$ ) (p = $0.001)$. The median FI value in the IUGR group became 40.0 (IQR 39.7-42.5) and the control group became 45.1 (IQR 44.1-53.1) ( $\mathrm{p}=0.012$ ). The median VFI became 2.2 (IQR 2.1-2.4) in the IUGR and 4.8 (IQR 4.4-5.3) in the control group, respectively. $^{8}$

Also, our results agreed with another prospective research involving 120 pregnant women; the normal pregnancy group comprised 100 patients from 22 to 42 weeks of pregnancy (average gestational age, 32.0 weeks). Twenty patients from 29 to 40 weeks of pregnancy enrolled in the IUGR pregnancy group (average gestational age, 33.5 weeks). In that study, the VI, FI, and VFI values were statistically substantially lower in the IUGR group relative to those in the normal group, which clearly showed that IUGR placenta complicated pregnancy had less blood vessels (lowered VI) and reduced blood flow (lowered FI) as well. Moreover, the findings showed that the placenta in IUGR pregnancy was lower on average by $92.66 \mathrm{~cm} 3$ compared to placenta in normal pregnancy. Their findings further suggested that the best criteria with the most beneficial discriminatory potential for adequate detection of IUGR pregnancies were VI and VFI. ${ }^{10}$

Also, Abule' et al., in 2016 found that all placental vascular indexes (VI, FI and VFI) were substantially decreased in extreme growthrestricted fetuses relative with the nomogram.

In the present study, hypertension in APS group was significantly correlated to placental volume in the 2nd scan which showed higher mean placental volume value in pregnant women with antiphospholipid with hypertension than in pregnant ladies with antiphospholipid with no hypertension. Nevertheless, no significant association was shown with other vascular indices, but placental index values were higher in pregnant ladies with antiphospholipid with hypertension than in pregnant ladies with antiphospholipid with no hypertension.

A case-control research was performed at Ain Shams University Maternity Hospital in 2015, contrary to the results of Mansour et al. In 80 preeclampsia pregnancies, assessment of placental vascular indexes was performed relative to 80 normal controls. In preeclampsia instances, there has been a statistical inverse association among albuminuria and VI $(p>0.05)$. The raised albumin associated with reduced vascularization supports the correlation of placental ischemia with maternal renal ischemia that is correlated with a rise in albumin in urine. ${ }^{7}$

From March 2011 to March 2013 in a prospective case-control analysis, Yuan et al. assessed 126 normotensive and 128 pregnant ladies with high blood pressure in 2015. He found that there was less intra-placental vascularization in hypertensive pregnant ladies relative to normotensive pregnancy, and intra-placental vascularization has been the nastiest in ladies with serious preeclampsia. Intraplacental vascularization did not vary from that of the normotensive group in gestational hypertension and non-severe preeclampsia. ${ }^{12}$

Another study evaluated 66 healthy pregnant women and 62 pregnant ladies and 62 pregnant ladies with
Obstetrics and Gynecology 
high blood pressure disorders and concluded that placental vascularization has decreased but not decreased placental volumes in pregnancies complicated by high blood pressure disorders. The intensity of the high blood pressure disorder seems to be associated with more pronounced decreased placental vascularization. ${ }^{9}$

\section{CONCLUSION}

From our study we could conclude that placental volume and indices of placental vascularization have been useful for assessing fetal well-being and predicting neonatal outcomes in pregnant ladies with antiphospholipid syndrome .

\section{REFERENCES}

1.Abule' RM, Bernardes LS, Doro GF, Miyadahira S, and Francisco RP. Reduced placental volume and flow in severe growth restricted fetuses. Clinics. 2016; 71(6):332-7.

2.Andonotopo W, Kristanto H, Dewantiningrum J, and Pramono BA. Difference between vascularization indexes of the placenta in severe pre-eclampsia and normal pregnancy by three- dimentional power Doppler ultrasound. Donald School J Ultrasound Obstet Gynecol. 2015; 329-35.

3.Anthony O. Odibo, MSCE, Katherine R. Goetzinger, Kristina M. Huster, JoAnn K. Christiansen, Linda Odibo, and Methodius G. Tuuli. Placental volume and vascular flow assessed by 3D power Doppler and Adverse pregnancy outcomes. NIH Public Access. 2012; 32(3): 230-4.

4.Chen CY, Wang KG, and Chen CP. Alteration of vascularization in preeclamptic placentas measured by three-dimensional power Doppler ultrasound. $J$ Matern Fetal Neonatal Med. 2013; 26: 1616-22.

5.Leavis, H., Zwerina, J., Manger, B. and Fritsch-Stork, R.D., Novel Developments in Primary Immunodeficiencies (PID)—a Rheumatological
Perspective. Current rheumatology reports. 2019; 21(10), p.55.

6.Gómez-Puerta JA, and Cervera R. Diagnosis and classification of the antiphospholipid syndrome. $J$ Autoimmun. Feb-Mar. 2014; 48 49:20-5.

7.Mansour GM, El-Mekkawi SF, Akl SA, and Abd El Khalek SY. Three-dimensional power Doppler indices of preeclamptic placentas correlated to umbilical artery Doppler and albuminuria. J Matern Fetal Neonatal Med. 2015; 28 (2):149-52.

8.Molnár A, Surányi A, Jakó M, Nyári T, and Németh G. [Examination of placental three- dimensional power Doppler indices and perinatal outcome in pregnancies complicated by intrauterine growth restriction]. Orv Hetil. 2017; 158(26):1008-13.

9.Pimenta EJ, Silva de Paula CF, Duarte Bonini Campos JA, Fox KA, Francisco R, Ruano R, and Zugaib M. Three-dimensional sonographic assessment of placental volume and vascularization in pregnancies complicated by hypertensive disorders. J Ultrasound Med. 2014; 33(3):483-91.

10.Pomorski M, Zimmer M, Florjanski J, Michniewicz J, Wiatrowski A, Fuchs T, and MilnerowiczNabzdyk E. Comparative analysis of placental vasculature and placental volume in normal and IUGR pregnancies with the use of three-dimensional Power Doppler. Arch Gynecol Obstet. 2012; 285(2):331-7.

11.Watkins WJ, Kotecha SJ, and Kotecha S. All-Cause Mortality of Low Birthweight Infants in Infancy, Childhood, and Adolescence: Population Study of England and Wales. PLoS Med. 2018; 13 (5):e1002018.

12.Yuan $T$, Zhang $T$, and Han Z. Placental vascularization alterations in hypertensive disorders complicating pregnancy (HDCP) and small for gestational age with HDCP using three-dimensional power Doppler in a prospective case control study. BMC Pregnancy Childbirth. 2015; 15:240. 